\title{
The Impact of the Student Counseling Center at Sultan Qaboos University on the Development of the Counseling Profession in Oman
}

\author{
Suad M. A. S. Al-Lawati ${ }^{1}$ \\ ${ }^{1}$ Ph.D in Counselor Educator (counseling), Department of Psychology, College of Education, Sultan Qaboos \\ University, Oman \\ Correspondence: Suad M. A. S. Al-Lawati, Ph.D in Counselor Educator (counseling), Department of Psychology, \\ College of Education, Sultan Qaboos University, Oman. E-mail: sulaiman@squ.edu.om
}

Received: August 27, 2019

Accepted: September 17, 2019 Online Published: September 18, 2019

doi:10.5539/ijps.v11n4p16

URL: https://doi.org/10.5539/ijps.v11n4p16

\begin{abstract}
Many factors play an essential role in establishing the profession of counseling psychology in Oman. These factors vary according to the country, culture, political environments, higher educational systems, university policy and regulations in which they arise. Current research and practice data prove the value of having counseling centers at universities for students, in terms of enhancing their personal development and adjustment skills, academic success, as well as improving student's general mental health and increasing successful graduation outcomes. Student Counseling Centers do not merely assist students in adjusting to university environments, but also play a vital role in improving their academic performances via helping them work through their academic problems, as well as supporting them through other mental health concerns, and many other issues that may arise among the students inside the campus. This paper will discuss the student counseling center's role in establishing counseling psychology profession in Oman.
\end{abstract}

Keywords: counseling psychology profession, counseling centers, mental health

\section{Introduction}

There is a growing need for counseling services around the world, particularly in the Arabic world, more so in Arab Gulf countries. The Sultanate of Oman has found itself in need of counseling services, due to the high digital development of technology and its rapid advances, as well as, quick changes in the knowledge economy and lastly the fourth industrial revelation. The tremendous exposure to other cultures today through social media and social networks exposes students undergoing different developmental stages to a wide range of challenges. Connecting with others online or via social media for longer hours, for instance, through smart phones creates social disorders such as nomophobia and phubbing (Anshari, et al, 2016). University students face a variety of issues on all levels. Some of these issues may involve difficulties in adjusting to university life, academic struggles pertaining to graduating, and lastly establishing their identities as adults. University and college counseling services have been serving a dynamic role in the overall mission of higher education from long period of time (Boyed et al., 2003). Moreover University and college counseling services have globally played a role in meeting the counseling needs of students, helping them succeed at their respective universities, and preparing them for their careers as well as, lives.

\section{University Counseling Centers}

University counseling centers have existed since 1920s through the 1940s. Counseling services were mostly provided by faculty, administrators, and other staff (Cooper, 2003). Pace, Stamler, Yarris, \& June (1996) note that University Counseling Centers (UCC) only started to address personal issues in the 1950s. Before the 1950s, their counseling services was most often limited to vocational counseling, which had emerged earlier to serve World War II veterans.

In the late 1960s W. H. Morrill and E. R. Oetting redefined university counseling center services in a developmental reframe work. Counseling center services benefit from community resources for mental health, and preventing mental health problems through providing developmental programs on campus. At the same time prioritizing individual counseling which takes the largest percentage of counselor's time. Further Pace, Stamler, Yarris, \& June (1996) articulate that in 1974 a Cube model was developed by W. H. Morrill a model 
served as conceptualization framework during 1980s. They add the cube model targeted individuals, primary groups, association groups, institution or community. Moreover, the purpose of the cub model was remedial, preventive, or developmental (Pace, Stamler, Yarris \& June, 1996). In addition, to the cube model target and purpose, the Cube model methods were direct, consultation and training or media. The Cube model required a balance between target, purpose and methods (Pace, Stamler, Yarris \& June,1996) ignoring the needs of students and university community as well as, the university policy. The researchers suggested that the global model consist of flexibility, interdependence, and collaboration with the university community (Pace, Stamler, Yarris \& June, 1996).

\section{The Need for Counseling at Sultan Qaboos University}

Many students at SQU (SQU was established in 1986 and was the first and only public University in Oman at the time) sought counseling from their advisors or counseling faculty members at the department of psychology in the college of education (prior to the establishment of the Student Counseling Center (SCC) in September 1999 (Sulaiman, 2002). Due to the university students pressing need for counseling, and an absence of an official student counseling center on campus, the counseling psychology faculty began providing counseling sessions in 1990 to their students in their offices, violating many professional and ethical standards.

Moreover, despite the availability of psychological and psychiatric services at the University Hospital (in the department of Behavioral medicine), students still preferred to seek help from counseling faculty members or in some cases, from their academic advisors at their college. While the students may have received useful advice and solutions from their designated advisors, they did not receive the professional counseling skills that they needed.

The academic advisors that were assigned to the students lacked the experience and the counseling qualifications required to deal effectively with their psychological problems, and thus could not fulfill their psychological needs (Al-Damen \& Sulaiman, 2004). In addition to lacking the appropriate qualifications and supervised training, the advisors did not follow the code of ethics that is so integral to the counseling profession. As a result, these services were jeopardizing the rights of counselees who were desperately seeking the counseling services.

Historically different disciplines held different views on what counseling was as a profession, and who the counseling should be provided by. Patterson (1928) declared that some educators advise that it is better for counseling to be provided by faculty members held the interest in providing academic supervision. Lioyed-Jones \& Smith (1938) mentioned that while some researchers believe that this faculty should obtain some general training in guidance to manage academic concerns, trained professional counselors should be the only ones to cope with student's psychological issues. In my study, Sulaiman (2008), I found that SQU student's scored low in terms of their level of shown satisfaction with academic advising services; the results also revealed that satisfaction levels on academic supervision and advising came in favor of male students, and for students in the colleges of Arts \& Social science, college of Science and college of Medicine. Such results indicated that male students were more satisfied than female students. Moreover, an achievement effect was prevalent. Students with average and below GPAS were more satisfied with their college academic advisors (Sulaiman, 2008). Academic advisors at colleges are equipped to assist students in planning and formulating academic plans, as well as, helping them overcome academic obstacles. They are not however, equipped to help them work through personal or psychological problems.

University students may face troubles, but lack the ability to solve their problems by themselves. Students may seek a counselor within their university, and may feel better once they receive the support they deserve. However, most of the students may spend a longer period in therapy, working through more serious mental health problems such as: anxiety, relationship troubles, depression, problems with appetite, sleeping problems, or difficulties adjusting to their new environment (Van Brunt, 2010). Regardless of their psychological problems, students experience difficulties accessing these counseling centers due to a lack of awareness of the physical existence of these services on campus (Van Brunt, 2010).

Shannon Hodges (2001) declared that it is crucial for counseling centers to exist in universities to provide the appropriate services to students, and that these services should be continuous. Certain factors make it more likely that a student would visit a counseling center; these primarily related to what the students actually thought about these centers. According to Flansburg (2014) gender is one of the factors that lead to the underutilization of counseling centers; female students are more likely to visit these centers seeking help. Flansburgh (2014) also found that females are more likely than their male counterparts to seek counseling regardless of whether they actually require mental health support. 
While male student's attitudes towards counseling centers were greatly different than female students. These attitudes may be related to the surrounding environmental factors in which the male students reside, or socially constructed notions of male masculine identities. Flansburg (2014) found that some students felt nervous about sharing their personal life with others, especially with people they met for the first time.

Additionally, a large number felt shame and were afraid that visiting a counselor may cause them embarrassment in front of their colleagues. Some students also held very negative ideas about counseling centers, believing them to only be for students who have mental and psychological illnesses; not realizing that counseling services were established for the average student.

These counseling centers hold sensitive positions in universities. As they provide the setting: in which the counselor provides the student with emotional support and guidance on how to deal with their academic and university-based issues. The counselor may also provide the student with emotional support in regards to their personal problems in addition to academic counseling (Boyd et al, 2003) The primary function of college or university counseling centers are to provide direct counseling services to students whose personal, academic, social and family problems interfere with their ability to continue their higher education. Despite the importance of providing counseling to students, the field of college mental health is less complicated than other fields (Meilman, 2016), however, retention data shows $40 \%$ of all college students leave college without a college degree (Tinto, 1993). University counseling centers help students' retention and assist them in graduating successfully. Hinderaker (2013) elaborate that counseling centers assist students in more than merely adjusting to university, but rather assists students in helping them improve their academic performance, solve their academic and personal problems, and supporting them through other mental health concerns like suicide, eating disorders, and a number of issues that may arise among the students.

\section{Establishing University Counseling Center}

In Oman at SQU, the proposal to establish the counseling center at the University was sent to the upper administration management in SQU several times since 1993 by Al Lawati. As Bishop (2010) points out the upper-administration management at universities were unaware of the benefits of counseling centers for students and university communities. Finally, after working through the political environment and decision- making process of the university to persuade the upper-management as advised in Bishop (2010)'s article, as well, engaging in many efforts to highlight the value of having counseling centers at universities for student development, adjustment, academic success, student's retention, risk management, graduation, positive mental health and economic return on investment, the SQU upper management administration approved the establishment of the student counseling center (SCC), and it was opened for students in September 1999.

As a publicly and governmentally owned university, tuition is free for students at SQU. In addition to free enrollment at SQU, students receive an additional allowance if they live fare away from the Muscat region, where the SQU campus is located. Food and Healthcare is free at SQU campus, and the individual and group counseling services provided by Student Counseling Center (SCC) are free.

Mental health awareness started in Oman since the establishment of the psychology department at college of education SQU in 1986. Faculty members at the department of psychology were providing lectures to various governmental units and voluntary associations. Counseling psychology as a profession emerged in 1999 at SQU, Oman. When the Student Counseling Center (the first counseling center in Oman) was established according to a comprehensive model of a college counseling center, but as an administrative and financial independent unit during the academic year of 1999-2000- (Sulaiman, 2006). The student counseling center provides students with developmental, prevention and remedial counseling services (individual and group counseling and psychotherapy). The developmental and prevention counseling services include: developmental guidance programs, outreach programs, on-line and phone consultation as well as, in-office consultation, workshops and training courses for students, faculty and staff, as well as, assessment and conducting research in the area related to student's academic, personal, social, family, career, and daily life problems related to their adjustment to the university or life at large. Moreover, the SCC provides training for counseling psychology graduates since 2017 .

The University Counseling Center according to Comprehensive Counseling Centre Model CCC provides a full range of services, including individual or group counseling services. The CCC provide consultations and collaborative services, outreach and preventive programs, training and education (Brunner, Wallace, Keyes, Polychronis, 2017). Rosenbaum \& Weatherford (2017) clarify that the CCC model is appropriate for larger universities. In smaller universities or colleges, excessively direct outreach and prevention programs threaten counseling services confidentiality, as well as the knowledge of services is embedded within college context. 
There are 17790 students enrolled at Sultan Qaboos University currently which makes the CCC model is appropriate for the Student Counseling Center.

The SCC mission states: "The Student Counseling Center was founded in 1999. The SCC provides a comprehensive program of support services to assist Sultan Qaboos University student's adjustment to the demands of the university environment. Our services are designed to enhance student's educational experiences by supporting their development. Our goal is to help our students grow, and help them widen their levels of self-understanding and awareness, so they are better able to meet the challenging demands of college life, and enjoy the college experience" (Student Counseling Center, undated). Each university should have its own plan on how to convince and encourage their students to visit counseling centers when they need help. It is important that students are made aware of the fact that these centers are confidential and their private information cannot be shared with others.

The SCC vision states: "The Student Counseling Center strives to be the most distinguished at a regional level in terms of its provision of counseling services as well as applicable research." The SCC's message states: "The Student Counseling Center works to achieve excellence in all aspects that are related to university life and the local community, specifically in the mentioned services; consultancy, training and research in the field of counseling. In addition, the SCC works to maintain leadership in quality services and to enhance the culture of help-seeking behavior for psychological services. It also seeks to promote mental health awareness. The student counseling center goals state:

1. Increasing awareness among students and fostering a connection between students and the services offered by the Center

2. Enhancing the culture of consultancy and help-seeking in the university's community.

3. Helping students to adjust and adapt to the university requirements through development, protection and training counseling programs.

4. Enriching students' educational experience by supporting their personal growth and their self-understanding, thus helping them become more conscious about their identity, characteristics, and abilities. As a result, equipping them with to be more able at facing life's demands.

5. Supporting students' positive personalities through individual and group counseling programs.

6. Supporting students in dealing with the challenges they encounter.

7. Providing training workshops to the students to help them become more successful in their studies and social lives.

8. Strengthening cooperation with the university and the community organizations in terms of counseling and psychological health.

9. Offering consultancy to students, the local community, as well as teaching and administrative staff at the university.

10. Conducting theoretical studies and research and then using its application to serve the university and the local community.

11. Participating in serving and developing the local community through the provision of several individualized counseling sessions and training workshops/courses.

12. Supervision of training for graduate student counseling psychologists.

The Student Counseling Center began with the possession of only four counselors in 1999. They were all highly qualified to provide counseling services, as all the counselors held a degree in counseling, three of which were a doctorate degree. The SCC served more than 1000 student yearly (SQU, 2005-2006). In addition to recruiting counseling professionals, four supporting staff were hired. Over time, the Sultan Qaboos University students counseling needs expanded rapidly, and to meet these needs, the SCC today's work staff expanded as well. There are 8 counselors who provide counselling to students, 4 of which hold doctorate degrees in counseling psychology, as well as 17 supportive staff, meaning a total sum of 25 personal. Counselors at the center practice and adhere to the counseling international guidelines and counseling code of ethics. 


\section{Counseling Profession in Oman}

\subsection{Student Counseling Center at SQU}

The Student Counseling Center at SQU has played a major role in the development of the counseling psychology profession in Oman, in terms of providing awareness about counseling services that are available to the students. (Sulaiman, 2004).The SCC's campaigns also spread intensive mental health awareness at the university committee, and the local society and community in Oman at large. The SCC was the first counseling center to be established at Sultan Qaboos University, as well as the first in all of Oman. At the time when the SCC was established in 1999, only psychiatric services were available to the public, in governmental hospitals only. The SCC was fully present on campus providing mental health awareness, positive psychology awareness, prevention and early intervention throughout outreach programs in collaboration with colleges and students societies activities, as well as, conducting weekly lectures, workshops, training which all played a vital role in efforts to de-stigmatize seeking counseling. Interestingly, after almost 20 years since its formation, a recent study on 1200 SQU students, via an online survey, revealed the existing stigma around seeking counseling among students has changed drastically among SQU students. The results of the study showed that the most prominent reason for not benefiting from the SCC services was " Asking for counseling help means that I suffer from a mental disorder" (Allawati \& Alrajhi, 2018). Moreover, the SCC provides free individual counseling sessions to the community as part of their community service.

The SCC published brochures and leaflets have helped students better adjust to their university environments. Of their handbooks include "Adjustment to University Life'. The "Adjustment to University Life" handbook was prepared a few years after opening the SCC as a means of assisting students' adjustments to academic and university life.

Moreover, two other handbooks were designed to help students; the first one includes a series of study skills such as: memorization, taking notes in lectures, effective reading, exam preparation and test-taking skills. The last handbook included a series of counseling leaflets that defined and explained essential psychological and counseling concepts such as; shyness, obsessive compulsiveness, depression, motivation and anger. These handbooks were perceived as beneficial by many students, and were claimed to enable them to successfully get through university and graduate (Sulaiman 2006, July 16-21).

Substantial efforts have been made to increase the awareness of counseling as a profession and to differentiate it from other professions. Such professions include as-psychiatry and social work which are very well established in Arabic countries, and the Omani community at large.

The abovementioned attempts at increasing awareness of counseling as a profession were accomplished by: (1) Offering presentations, lectures, and publishing research papers that elaborate the importance of counseling and mental health to different schools, colleges, universities and other organizations during conferences, symposiums, exhibitions.

(2) Writing articles and publishing a weekly column in a national official newspaper about counseling as a means of increasing mental health awareness. (3) Participating in local interviews via Radio and Television programs, as a means of establishing a dialogue about counseling psychology as a profession and the importance of spreading awareness of mental health, and its impact on being able to positively change a human's life. (4) Initiating a study skill course (the study skill course is currently an online elective course for SQU students.) with the college of education for SQU students. The course material was prepared by the SCC counseling staff from the College of Education. This was followed by a pilot study to measure the student's GPA before, and after the study skill course. The results showed an improvement in the student's GPA and this demonstrated the importance of study skill courses to higher and upper administration.

To maintain the professional counseling standards, ethical codes (APA \&ACA for counseling profession) were translated into Arabic and modified to adapt to Arabic and Omani culture to regulate counseling practices in 2005. A committee was established at SCC to accomplish translating, reviewing and modifying the counseling code of ethics. The theoretical framework for the conditions, organized systems and the standards which control the rights and duties of the counselee, counselor and related issues were reviewed and established according to the Arabic version of the code of ethics

The code of ethics booklet was distributed to several educational institutions in Oman, Arab Gulf countries, and Arab countries. These ethics booklets were mailed directly to them, or distributed through the first symposium of guidance and counseling conducted by SCC, SQU, (4-5 December, 2005). Publishing a booklet of the Arab code of ethics prevented the counseling profession from various malpractices, and protected counselee's rights. 
Moreover, it has also prevented local community centers (developmental, educational, consultation etc.) whose staff do not have the necessary qualifications from offering unprofessional counseling services. This was critical to the sustainability of the quality of control of the profession. Recently when I directed the SCC again the code of ethics booklet was reviewed and revised again by a committee included counselors at SCC in 2015, and was approved by the SQU university board (University Council) to be mandatorily implemented at all SQU units in April 2019, as well as being incorporated into the SQU bylaws. "The Policy of Student Counseling" was approved by upper-management in 2017 and was incorporated into SQU bylaws. Moreover the SCC director has been a member of the International Association of Counseling Centers Association for University and College Counseling Centre Directors since 2000.

As a result, of the upper-management's goals for seeking accreditation for different colleges at SQU, and maintaining a high standard. The Student Counseling Center started seeking accreditation through the professional organization International Association of Counseling Services (IACS) in USA. The Student Counseling Center received accreditation from the IACS in April 2019, and was the first government university in the Arabic Gulf, as well as first Arabic country in total to receive accreditation.-

In the present moment, Oman lacks a national professional counseling body or association. However, it is worth noting that there are various efforts to establish a national committee consisting of the participation of both the Ministry of Health and Ministry of Social Affairs and the Sultan Qaboos University as a means of being able to establish professional counseling licensure (according to International standards).

\subsection{The Quality Improvement of UCC}

Muffini and Toth (2017) discuss the importance of ensuring consistent quality improvement (QI) in university counseling centers for stockholders as well as upper-administrators to insure the positive outcomes of counseling. Muffini and Toth (2017) recommend different QI strategies such as: satisfaction surveys, outcome studies, chart review, evaluation review, and intern projects. Muffini and Toth (2017) also confirm that the quality improvement (QI) assessment varies from one university counseling center to another.

To insure the quality standards of the SCC services at SQU different QI strategies were implemented to measure them. Of the various strategies, one strategy involved conducting studies to measure student's perceptions as well as, faculty and staff attitudes towards the SCC's environment, counseling services, and counseling staff.

The results of the first study has given an insight about the quality levels of the SCC services such as: the SCC's environment, individual and group counseling, developmental programs, outreach counseling, discussion sessions, and student workshops. The results indicated that the services were ranked to be of a very high level of quality (Allawati \& Alrajhi, 2018).

The findings of the second study confirmed that 224 faculty and staff members held positive and obliging attitudes towards the SCC and its services. In addition, high positive attitudes were also found towards the importance of counseling as profession, counselors, and counseling services (Alrajhi \& Al.Lawati, 2018).

The second QI strategy is the study's results of counseling services and programs (Muffini and Toth, 2017). To measure SQU student's counseling needs, SCC programs such as: outreach programs, workshops, trainings and so on play a fundamental role in assisting the SCC administration in preparing programs according to student's needs. Al Damen and Sulaiman's (2007) study on Sultan Qaboos University (SQU) students revealed that students experience counseling needs at all levels; the academic needs often come first, followed by psychological needs, then career and vocational needs. Counseling needs at SQU vary by college and gender, as students from the college of humanities as well as female students appear to have greater needs. Students reported the following counseling needs: to improve; academic motivation, academic achievement, self-confidence, independence, computer skills, relationships with faculty, abilities and potentials, memory skills, conversation management, and decision making skills.

The study found that students need counseling services to assist them in their academic, social, career, emotional, personal development and growth (Al Damen \& Sulaiman, 2007). Moreover, university students need assistance in learning to adjust academically, personally and socially to university life, as well as in gaining problem solving and decision making skills (Al Damen \& Sulaiman, 2007). It is believed that such skills may benefit them later in their occupational and personal lives.

Another study claims that students with higher GPA's exhibited higher levels of academic stress, quickly followed by psychological stress compared with students with lower GPAs. This appears to reflect the anxiety and internalized pressure they feel to maintain and surpass their high GPA or grades (Sulaiman \& Al- Damen, 
2004). It was shown that higher achievers are exposed to a high level of academic stressors followed by many psychological stressors. This appears to be equally prevalent for both genders.

Sulaiman \& Al- Damen (2004) explain the reasons for these patterns to be due to: exam difficulties, excessive study requirements, the difficulty of some subjects, test anxiety, time management strains, lack of adequate leisure time, failed attempts to meet parent's high expectations, difficulties in registering classes, and the overwhelming fear of not finding a job after graduation. (Sulaiman \& Al- Damen, 2004). Female students reported experiencing a higher number of daily stressors than male students. While female students held similar academic stressors to male students, their psychological stressors were greater than their male counter parts, and included some of the following: test anxiety, feeling exhausted, feeling insecure about their abilities, lack of unanimity between students, feeling depressed, excessive shyness when presenting their work or projects (Sulaiman \& Al- Damen, 2004). University students may experience stress, anxiety and other psychological problems such as depression as a result of being exposing to a wide range of stressors including: adjustment to university difficulties, overwhelming academic work, strained or troubled interpersonal relationships, and overly high expectations from significant people in their life.

Sulaiman and El- Mneizel (1999) note that the abovementioned experiences can play a role in effecting their adjustment and achievement levels. However, a number of students find themselves more able to adjust by the second semester (Sulaiman, El- Mneizel, 1999). The previous findings indicate that even students who are high achievers may need and require counseling services from counseling centers at universities to help them with anxiety reduction and stress management. There has always been a need for counseling services at SQU in Oman and that need has grown significantly by time.

The previous findings showcase the need for counseling services in certain fields such as study skills, time management, anxiety management, self-confidence, social skills, dealing with shyness, retention and depression.

Interesting findings of Alrajhi \& Al-Lawati (2018) study on 1156 SQU (over a period of 11 years) students confirmed that students experience counseling needs at all levels; the psychological needs coming in first. The psychological needs were expressed in statements such as : "getting red from uncomfortable thoughts and obsessive thoughts", "understand the strong and weak points I have", followed by academic needs being expressed in statements such as: "studying regularly every day" "to learn effectively managing time", as well as social needs being expressed in statements such as "improving my ability to express myself in front of others" " the ability to adjust to university life and family needs such as: "participate to take decisions with family" " learning how to deal with family problems". However, the social and family needs were assessed to be of lower priority and recurrence than the other needs.

The existence of counseling services at universities and colleges at counseling centers are key in helping students achieve healthy lives, preventing them from psychological disorders, as well as, providing counseling and therapy to students when needed. The third QI strategy involves an evaluation review for all programs (Muffini and Toth, 2017). Since the establishment of SCC, the outreach programs, workshops and training courses are followed by an evaluation sheet that is filled out by the attendees and beneficiaries. These evaluation sheets are then analyzed and presented to the staff at the staff meeting, as well as to upper administration through the SCC annual report.

The evaluation of SCC services during the academic year of 2016- 2017 demonstrated that of the students who attended the 11 group counseling sessions (GCS) at SCC, 98\% of them rated GCS as excellent, and $2 \%$ rated it as good. Moreover, of the students who attended the 14 developmental programs (weekly lectures) which were provided by SCC Staff, $48 \%$ of the students rated it excellent, $42 \%$ rated it very good, $8 \%$ rated the programs as good, and $1 \%$ rated them as medium. Additionally, $73 \%$ of the students gained knowledge about the developmental programs through e-mail, $0 \%$ by SMS, $19 \%$ through friends, $7 \%$ through advertising boards, and only $1 \%$ of the students found out about the program through SCC social media accounts such as Instagram, Twitter, and Facebook. Moreover, the SCC staff conducted 11 outreach programs, and 8 discussion sessions in coordination with different colleges at SQU. Of the students who attended 9 workshops; $63 \%$ were highly satisfied and $34 \%$ were satisfied with the contents of the workshop. Moreover, $58 \%$ were highly satisfied while $40 \%$ were satisfied with the activities of the workshop. In addition, $73 \%$ were highly satisfied, and $25 \%$ were satisfied with the services. Moreover $74 \%$ of students were highly satisfied, and $24 \%$ were satisfied with training counselor who provided the training at the workshop. Statistics show that 4704 students (26.4\% of the students) at SQU benefited from SCC services during the academic year of 2016- 2017 (Student Counseling Center, 20162017). The Student Counseling Center at SQU is an example of a UCC model for the universities and colleges in Oman, GCC countries, and other Arab countries 


\subsection{Other Efforts to Establish Counseling as a Profession}

Other efforts were conducted to establish counseling as a profession in Oman. Of these efforts included the establishment of a research committee under the Ministry of Education to study the developmental role of social workers in schools and to study the to provide psychological and career counselors for students at schools (1999-2001). This committee was established with the purpose of convincing policy makers at the Ministry of Education about the importance of offering counseling services in schools by appointing counselors in each school in Oman. The committee performed three fields of research (Sulaiman, 2001):

Studying the social workers $(\mathrm{N}=120)$ role \& job duties in the schools.

Studying student's problems in schools (representative sample from all regions, $\mathrm{N}=1872$ ).

Studying student's problems in schools from the point view of school administrators, teachers, \& social workers (representative sample from all regions, $\mathrm{N}=334$ ).

The results showed the vast difference between social workers and counselors job duties at schools. The results of the collective studies seem to indicate that from the perspective of the school administrators, teachers, social workers and the students themselves; the students were experiencing problems at school. A final report was presented to the upper-administration at the Ministry of Education as a means of highlighting the necessity of appointing counselors in every school (alongside the existing social workers) because social workers cannot replace the counselor, and have differing professional's duties and roles from counselors.

Other efforts included the proposal of establishing the national center for career guidance and counseling. This proposal was sent to the Ministry of Education in 1999 by myself, Dr. Suad Al-Lawati. The Ministry of Education then referred the proposal to the Ministry of Social Affairs and Labor and Vocational Training. It was here that the need of establishing a center that provides career guidance and counseling for all job seekers at all education levels was highlighted. The center was established as an independent body, and was later transferred under the jurisdiction of the Ministry of Education and opened in 2006. At the end of the academic year, the ministry of education created a position for career guidance personnel in all schools in Oman. Since the year 2007, the ministry of education actualized its strategic plan of appointing career guidance counselors in each and every school in the Sultanate of Oman as a means of offering career counseling services to all students. In the academic years 2008-2009, A diploma in career counseling was offered to students at the department of psychology (SQU), followed by a Master's program in the academic years 2013-2014, this was done to meet the career guidance and counseling demands created by the newly appointed positions at governmental schools.

The Ministry of Higher Education in Oman has taken a big step forward by establishing counselor positions and appointing counselors in all their educational and technical colleges. This led to an increase in job opportunities in the counseling field. This initiative was further reinforced by the ministry through their efforts in providing the Omani population with opportunities for higher education studies in counseling (through the provision of scholarships), outside of Oman.

The University of Nizwa, a private university, established a graduate program in counseling psychology in 2006-2007. Other universities such as Dhofar University followed suit, and founded a Master's program in 2014. Many newly established private universities have either established counseling centers or appointed professional counselors, such as National University and Sohar University.

The increase of mental health awareness in the public led many private counseling centers and mental health clinics to open in various regions of Oman. These centers/clinics often provide consultation and counseling separately, or in combination with psychiatric services to the public. The first psychiatric private clinic Top Medical Care was founded in 2003 in Muscat, Oman. Alternatively, the first private office that provided consultations was established in 2012 under jurisdiction of the Ministry of Commerce. However, the permit was later transferred from the Ministry of Commerce to the Ministry of Social Affairs. The first center for consultation and counseling was opened in 2016 in Muscat.

\section{Conclusion}

In the 1990s, the existence of counseling services for university students were seen as unnecessary, and it was tremendously difficult to convince administrators, faculty, and other staff of the importance of counseling services for university students at Sultan Qaboos University. Launching the first counseling center in 9 September 1999 according to the international standards of the counseling profession and providing of awareness of mental health issues, and many other efforts to expand and extend counseling profession in Oman. Today after over 20 years counseling is a sound and established profession around the country. There is a bright future for counseling as a profession in Oman. In the near future, a professional counseling association will be 
established as a division of Omani Psychology Association OPA (the proposal to establish OPA is under review at the authorized organization, Ministry of Social affairs) or may be as Omani Counseling Association to enhance counseling profession further in Oman and maintain the ethical standards.

\section{References}

Al- Damen, M \& Sulaiman, S. M. A. (2004, March 6-7). The role of the academic advising in student development, SQU, Sultanate of Oman.

Al-Damen, Monther. \& Sulaiman, S. M. A. (2007). The Counseling Needs of Sultan Qaboos University Students. Journal of Educational and Psychological Sciences, Bahrain, Almujaled, 8(4), 161-178.

Alrajhi, M. N. \& Al.Lawati, S. M. (2018), Faculty and staff attitudes towards student counseling center and its services. International Journal of Psychology and Behavior analysis, 4, 144-150.https://doi.org/10.15344/2455-3867/2018/144

Alrajhi, M. N. \& Al.Lawati, S. M. (2018). Counseling needs among Sultan Qaboos university students in the light of some demographic variables. International journal of learning and management system, 6(2), 99-118. (in Arabic)https://doi.org/10.18576/ijlms/060204

AL.Lawati, S.M. \& Alrajhi, M. N. (2018). Quality of student counseling centre's services at Sultan Qaboos University: Students' Perceptions. Australian Counseling Research Journal, 12(2), 13-22.

Anshari, M., Alas, Y., Hardaker, G., Jaidin,J. H., Smith, M. \&Ahad, A. D. (2016). Smartphones hapit and behaviour in Brunei: Personalization, gender, and generation gap. Computers in Human Behaviors, 64, 719-727.https://doi.org/10.1016/j.chb.2016.07.063

Bishop, J. B. (2010). The counseling center: An understanding resource in recruitment, retention, and risk management. Journal of College Student Psychotherapy, 24(4), 248-280.https://doi.org/10.1080/87568225.2010.509219

Boyed. (2003). Council for the Advancement of Standers in Higher Education, 2009; DeStefano. Petcrsen, Skwerer \& bickel, 2001; Gallagher, 2009.

Brunner, J., Wallace, D., Keyes, L. N., Polychronis, P. D. (2017). The Comprehensive counseling center Model. Journal of College Student Psychotherapy, 31(4), 297-305. https://doi.org/10.1080/87568225.2017.1366167

Cooper, S. (2003) College counseling centers as internal organizational consultants to universities. Consulting Psychology Journal: Practice and Research, 55(4), 230-238. https://doi.org/10.1037/1061-4087.55.4.230

Flansburg, Terri. (2012). Factores Involved in College Students' Use of Counseling Services. Master of Social Work Clinical Research Papers. Paper 23.

Hinderaker, Daniel J. (2013). College Student Mental Health and Use of Counseling Center Services. Master of Social Work Clinical Research Papers. Paper 190.

Hodges. S. (2001). University Counseling Center at the Twenty-First-Century: Looking Back. Journal of College Counseling, 4(2), 161.https://doi.org/10.1002/j.2161-1882.2001.tb00196.x

Lin, Y. (2014). College Psychotherapy at Taiwanese Counseling Center. Journal of Student Psychotherapy, 28(1), 6-11. https://doi.org/10.1080/87568225.2013.824321

Lioyd-Jones E.McD. \& Smith, M.R. (1938). A Student Personal Program for higher education. New York: McGraw-Hill.

Maffini, C.S. \& Toth, P. L. (2017). Quality Improvement in University counseling centers. Journal of college Student Psychotherapy, 31(1), 43-58.https://doi.org/10.1080/87568225.2016.1254000

Meilman, Philip. W (2016). Pressures we face in running counseling centers on college and university campuses. Journal of college Student Psychotherapy, 30(1), 1, 7-11. https://doi.org/10.1080/87568225.2016.1105641

Rosenbaum, P. \& Weatherford, R. D. (2017). Models of a counseling center and the importance of context. Journal of college Student Psychotherapy, 31(4), 265-267.

Pace, D., Stamler. V. L., Yarris. E. \& June, L. (1996). Rounding out the cube: Evolution to a global model for counseling centers. Journal of Counseling \& Development, 74(4), 321-331.https://doi.org/10.1002/j.1556-6676.1996.tb01874.x

Student Counseling Center. (2016-2017) Unpublished Annual Report. Sultan Qaboos University. 
Sulaiman, S. M. A. (2001). The developmental role for social worker in schools and studying to provide psychological \& career counselors. Un- published report.

Sulaiman, S. M. A. (2002, February 11-12). The role of students counseling center at Sultan Qaboos University. A counseling \& guidance symposium conducted at the $15^{\text {th }}$ meeting of the Deans of student's affairs in Arabian Gulf Countries, Kuwait University, Kuwait.

Sulaiman, S. M. A. (2004, February15-16) The role of counseling centers in institutions of higher education: the role of student counseling center at SQU. Rustaq College, Ministry of Higher Education, Sultanate of Oman.

Sulaiman, S. M. A. \& Al-Damen, Monther. (2004). The relationship between student's stresses and census variables at Sultan Qaboos University in the Sultante of Oman. Egyptian Journal for Psychological Studies, 14(44), 1-19.

Sulaiman, S. M. A. (2006, May13-15) Student counseling center as a model for counseling centers in higher education. The first symposium of career guidance. Ministry of Education, Sultanate of Oman.

Sulaiman, S. M. A. (2008). Satisfaction on academic supervision services among Sultan Qaboos University Students. Journal of Educational Sciences, Almujaled, 9(2), 13-38.

Sulaiman, S. M. A. \& El-Mneizel, A. F. (1999). Adjustment level among Sultan Qaboos University Student's \& the relationship to sex, class level, grade point average and residency. Derasat (An International Refereed Research Journal), Educational Sciences, University of Jourdan, 26(1), 1-18.

Sulaiman, S. M. (2006, July 16-21) Starting from scratch: College counseling in Oman: College counseling center in global perspective, Research Paper presented at the $26^{\text {th }}$ Congress of Applied Psychology. Athens, Greece.

Sulaiman, S. M. (1999). Prepare a study for the project to establish a National Center for Career Guidance, Ministry of Education \& the Ministry of Social Affairs and Labor and Vocational Training. Un- published report.

Sultan Qaboos University. (2005-2006). Annual Report. University press, Sultanate of Oman.

Tino, V. (1993). Leaving college: Rethinking the causes and cures of student attrition $\left(2^{\text {nd }}\right.$ ed). Chicago: University of Chicago Press. https://doi.org/10.7208/chicago/9780226922461.001.0001

Van Brunt, B. \& ACCA PAPA Committee. (2010). The preparation and role of college counselors (ACAPCD-36). Alexandria, VA: American Counseling Association.

\section{Copyrights}

Copyright for this article is retained by the author(s), with first publication rights granted to the journal.

This is an open-access article distributed under the terms and conditions of the Creative Commons Attribution license (http://creativecommons.org/licenses/by/4.0/). 